\title{
Individual Incremental loading factor based maximum loadability limit prediction using modern optimization tools
}

\section{DOI : 10.36909/jer.11507}

\author{
S. Manohaaran*, K.Gnanambal** \\ *Dept of Electrical and Electronics Engineering. K.L.N College of Engineering, India, \\ sharpmano@gmail.com \\ ** Dept of Electrical and Electronics Engineering. K.L.N.College of Engineering, India \\ gnans_balu@rediffmail.com
}

\section{Abstract}

Infrastructure innovation in the power system industry encourages more partakers to participate in the electricity market which improvises the load utilization level. So, the maintenance of power system's agility with respect to any dynamic update in terms of load level is necessary. Precise prediction of maximum allowable loading point helps to enhance the power system agility and also improvises the total allowable power transfer capability which in turn helps to supply continuous eminent power supply at the minimal cost to the customers by means of encouraging more contracts. Considering the above potential benefits, in this papear by using individual incremental loading factor (IILF) the precise prediction of total loadability limit (TLL) of the system is manipulated with the help of newly evolved meta-heuristic optimization algorithm such as Grey Wolf (GRW) optimizer and Flower Pollination Algorithm (FPA). The allowable single line contingency scenario is considering along with base case scenario to extract the more realistic TLL which helps to maintain the power system balance with respect to the dynamic nature of the load. The proposed maximum loading point extraction manipulation solution problem is tested with the help of three standard IEEE systems such as 30 Bus, 57 Bus and 118 bus systems. The extracted test results show that the predicted maximum allowable loading point enhances the load utilization level without affecting the system securities. The statistical performance measures of GRW and FPA confirmed the better balance of exploration and exploitation in extracting the optimal results.

Keywords: Individual Incremental Loading Factor (ILF), Total Loadability Limit (TLL), Grey Wolf (GRW) Optimizer, Flower Pollination Algorithm (FPA), Reapeted Power Flow (RPF)

\section{Introduction}

The healthiness of any power system is to a large extent dependent on the balanced power supply with respect to any dynamic load utilization and with the restoration rate level in case of any contingency. So, the 
essential roles of any power system operation and control is to pre-determine the maximum allowable demand at each existing load bus as well as in pre-categorizing the critical load buses and transmission lines in a power system. The function of determining maximum allowable demand of each load bus in a power system helps to extract the maximum allowable Total Loadability Limit (TLL) of a power system. TLL extraction process not only resolves the operation-based problems, but also provides constructive information for the distribution expansion planning, distributed generation sizing, tie-line capacity, FACTS device placements, etc., [1-5]. According to power system operational stance, the allowable TLL is the maximum load limit that a power system can serve the customers without violating any security constraints. Maximum loadability limit (MLL) based analysis is one of the best approach to appraise a power system in a steady state and also pre-determine the practical intellect of a security margin [6]. In the restructuring based deregulated electricity environments, power systems are often heavily traffic with high load utilization which may results in higher affinity toward instability. So, the prediction of MLL helps to provide reliable electric supply to the consumer without any contract violation and also at the optimal cost. Different mathematical models and optimization techniques, like classical, heuristic, and hybrid methods have been proposed to estimate MLL [7-11].

The progressive increase in the electric power demands until convergence methodology of conventional power flow has been followed at the initial stage in extracting the MLL [12]. In modern years, in order to find the appropriate MLL, OPF and Security Constrained Optimal Power Flow (SCOPF) based models have been widely used which plays an important role in power system operation, decision making, and market driven based problems [13-15]. OPF-based model has been presented in [16], as an extension of the power flow-based model in [17]. Even though finding the MLL using conventional power flow tools is well established problem but the conventional methodology needs lot of pre-analysis and also need lot of manual arbitration in knowing MLL [18,19]. Another complexity in the area of MLL research is that the enrichments to power flow-based approaches cannot be correctly applied which consider more practical network constraints [20]. Also, the usage of conventional optimization algorithm increases the mathematical stress and difficulty in handling the mixed data types such as integer, float and binary as a group control parameters.

The application of meta-heuristics based evolutionary optimization algorithm such as Genetic algorithm (GA), Particle Swarm Optimization algorithm (PSO) etc., provides the breakthrough for handling the mixed data types in all the complex power system problems. Due to its parameter handling capability with respect to any 
number of dimensions, the optimal maximum loadability limit is determined using Hybrid PSO by considering the voltage limits as security constraints in each load buses. The voltage stability limit is the nose point of the PV curve after which the voltage collapse occurs. In the same paper, the load is uniformly incremented at all the load buses until bus voltages are violating [21]. In practical, the loadability level at each load bus will differ with respect to the congestion level of the bus. Hence, the dynamic incremental variation at all the load buses is necessary to predict the allowable MLL of any power system [24]. In literature [25], the Hybrid DEPSO algorithm was proposed to determine the maximum loading point by incrementing each load bus with variable loading factor under static condition. Due to the inherent nature of the power system such as overloading, transmission line disturbances and protection device failures, there is a high possibility of the contingency occurrence. Hence, the study of contingency based TLL extraction at each load buses is very much essential in the highly stressed power system to prevent any kind of uncertainties. Very Few literatures are available to determine the MLL of the power system by considering the contingency analysis. Analyzing the above difficulties, in this paper TLL of a power system is predicted by optimally extracting the individual incremental loading factor (IILF) for each load at the base case scenario and also at the single transmission line outages scenario. The Severity of the line contingency depends upon the least TLL differs from the base case scenario. In this proposed research work, newly evolved nature inspired highly balanced search based Grey Wolf (GRW) Optimizer algorithm [26 - 28] and Flower pollination algorithm (FPA) [29] are applied to extract the optimal loading factor of each load bus by satisfying the equality and inequality security constraints such as bus voltage limits, transmission line limits and power balance constraints with and without line outages. To test the effectiveness of the proposed approach and the robustness of the applied optimization algorithms, three different standard test systems such as IEEE 30, 57 and 118 are utilized and their test results are compared.

\section{Individual Incremental Loading Factor (IILF) based problem formulation}

Individual Incremental Loading Factor (IILF) method helps to predict the maximum load that can be added at each existing load bus. The pre-determination of each load demand helps to identify the stress level of the power system in the existing loading condition and also helps to improve the loadability utilizing level which in turn enhances the possibility of the economic contractual plan in any competitive electricity market. Therefore, the individual incremental loading factor method helps to determine the optimal allowable total loadability limit of the system which has been described in the following sections 


\subsection{Optimal mathematical Total Loadability Limit (TLL) objective Formulation at base}

\section{case scenario}

The main objective of the proposed problem is to extract the maximum secured Total Loadability Limit (TLL) in a power system via IILF determination at each load. To extract the proposed objective results, the following mathematical equation (1) has been modeled as follows

$\mathrm{F}_{1}=\operatorname{Max}(\mathrm{TLL})=\operatorname{Max}\left(\sum_{\mathrm{i}=1}^{\mathrm{NLB}}\left(1+\lambda_{\mathrm{i}}\right) * \mathrm{P}_{\mathrm{di}}\right)$

Where TLL= Total loadability limit of the system

$\lambda_{\mathrm{i}}=$ Individual Incremental loading factor at each load bus

NLB is the Number of Load Buses

Subject to

Constraints1: Power balance equations

$$
\begin{aligned}
& \mathrm{P}_{\mathrm{gi}}-\left(\mathrm{P}_{\mathrm{di}}+\lambda_{\mathrm{i}}\right)-\sum \mathrm{V}_{\mathrm{i}} \mathrm{V}_{\mathrm{j}} \mathrm{Y}_{\mathrm{ij}} \cos \left(\theta_{\mathrm{ij}}+\delta_{\mathrm{j}}-\delta_{\mathrm{i}}\right)=0 \\
& \left(\mathrm{Q}_{\mathrm{gi}}-\mathrm{Q}_{\mathrm{di}}\right)-\sum \mathrm{V}_{\mathrm{i}} \mathrm{V}_{\mathrm{j}} \mathrm{Y}_{\mathrm{ij}} \sin \left(\theta_{\mathrm{ij}}+\delta_{\mathrm{j}}-\delta_{\mathrm{i}}\right)=0
\end{aligned}
$$

Constraints2: Voltage profile constraint

$$
\mathrm{V}_{\text {imin }} \leq \mathrm{V}_{\mathrm{i}} \leq \mathrm{V}_{\text {imax }}
$$

Constraints3: Real and reactive generation power constraints

$$
\begin{aligned}
& \mathrm{P}_{\text {imin }} \leq \mathrm{P}_{\mathrm{i}} \leq \mathrm{P}_{\mathrm{imax}} \\
& \mathrm{Q}_{\text {imin }} \leq \mathrm{Q}_{\mathrm{i}} \leq \mathrm{Q}_{\text {imax }}
\end{aligned}
$$

\subsection{Optimal mathematical TLL objective formulation considering contingency scenario}

Due to the sudden technical inconsistency such as overloading in load buses, power conversion device failure, unbalanced system faults etc., will impose high probability of transmission line outage from the power system. Therefore, there should be high concern in considering the transmission line outage while extracting the maximum loadability of the system. Highly sensitive transmission line outages are also possible i.e. the line outage which will not even allow increment a MW of the power demand in the base case system level. These highly sensitive transmission lines are not considered for extracting the maximum loadability. The inclusion of line outage in extracting the maximum loadability of the power system will newly define the objective function (7) as provided below 


$$
\left[\mathrm{F}_{2,} \text {,index }\right]=\operatorname{Min}(\operatorname{Max}(\mathrm{TLL}))=\operatorname{Min}_{0 \leq \mathrm{j} \leq \mathrm{NLO}}\left\{\operatorname{Max}\left(\sum_{\mathrm{i}=1}^{\mathrm{NLB}}\left(1+\lambda_{\mathrm{i}}\right) * \mathrm{P}_{\mathrm{di}}\right)\right\}
$$

Where index is the line outage corresponding to min of max TLL which identifies the weakest line outage leads to no further additional loading

\section{Optimization Algorithm Structure}

The established positive efficiency of meta-heuristic Optimization such as Genetic Algorithm (GA), Particle Swarm Optimization (PSO), Differential Evolution(DE), FireFly algorithm (FFA) and Simulated Annealing (SA) in solving complex non-convex, multi-dimensional and multi variable power system increases the involvement of evolutionary, swarm based intelligence and nature inspired algorithms in obtaining various power system problem solutions in the last decade. The improved application of the meta-heuristics algorithm in modern power system engineering application paves the way for the evolution of many new nature inspired algorithm with quick search capability and with the better balance search technique. Grey Wolf (GRW) Optimizer and Flower pollination algorithm (FPA) are best among the recently evolved highly balanced search meta-heuristics algorithms.

\subsection{Grey Wolf (GRW) Optimizer}

Grey Wolf (GRW) Optimization is a newly evolved optimization framework inspired by Canadian grey wolves developed by Mirjalili [27]. The solutions of the GRW algorithm in non-convex engineering optimization problems proven to attain better search results compared to well established DE, PSO and GA based optimization methods. The search space flow process of the GRW algorithm is directed by three wolves, namely alpha $(\alpha)$, beta $(\beta)$ and delta $(\delta)$. Alpha $(\alpha)$ is the leader of the grey wolves these may be a male or female, whereas the beta is the second level dominant grey wolves which advices the alpha in terms of process execution and also shares the instruction to the third level dominant delta wolves. All the process is implemented by omega $(\omega)$ wolves under the guidance of the delta wolves. So, the omega wolves' positions are ordered according to the three dominant grey wolves' positions. The three major phase of grey wolf hunting are tracking, encompassing and attacking the prey. These three dominant wolves will guide the omega wolves to identify the prey during hunting. Once the prey gets identified, the omega wolves will encircle and troublesome the prey until it stops moving. Based on the three phases of GRW hunting process, the solutions are designed in such a way that the global best fitness value are always extracted from the alpha $(\alpha)$ solutions consequently the second and third best fitness ones i.e. local best fitness

values are extracted from the beta $(\beta)$ and delta $(\delta)$ solutions. The above three alpha, beta and delta solutions helps to narrow the search space criteria in identifying the best solutions which provides the exploration concepts in search 
methodology. Later, the solutions are exploited in the newly identified search space to extract better solutions. As mentioned above, the mathematical modeling of prey encircling behavior are proposed as follows

$\overrightarrow{\mathrm{D}}=\left|\overrightarrow{\mathrm{C}} \cdot \overrightarrow{\mathrm{X}}_{\mathrm{p}}(\mathrm{t})-\overrightarrow{\mathrm{X}}(\mathrm{t})\right|$

$\vec{X}(t+1)=\vec{X}(t)-\vec{A} \cdot \vec{D}$

Where $t$ indicates the current iteration, $\vec{A}$ and $\vec{C}$ is coefficient vectors, $\vec{X}_{p}$ is the position vector of the prey, and $\vec{X}$ indicates the position vector of a grey wolf.

The vectors $\vec{A}$ and $\vec{C}$ are calculated as follows:

$\vec{A}=2 \vec{a} \cdot \vec{r}_{1}-\vec{a}$

$\overrightarrow{\mathrm{C}}=2 \cdot \overrightarrow{\mathrm{r}}_{2}$

Where components of $\vec{a}$ are linearly decreased from 2 to 0 over the course of iterations and $\mathrm{r} 1, \mathrm{r} 2$ are random vectors in the range of $[0,1]$. The hunting knowledge of the three best wolves helps the omega wolves to identify the prey position. Based on the same, the mathematical model has been described as provided below

$\overrightarrow{\mathrm{D}}_{\alpha}=\left|\overrightarrow{\mathrm{C}}_{1} \cdot \overrightarrow{\mathrm{X}}_{\alpha}-\overrightarrow{\mathrm{X}}\right|, \overrightarrow{\mathrm{D}}_{\beta}=\left|\overrightarrow{\mathrm{C}}_{2} \cdot \overrightarrow{\mathrm{X}}_{\beta}-\overrightarrow{\mathrm{X}}\right|, \overrightarrow{\mathrm{D}}_{\delta}=\left|\overrightarrow{\mathrm{C}}_{3} \cdot \overrightarrow{\mathrm{X}}_{\delta}-\overrightarrow{\mathrm{X}}\right|$

$\overrightarrow{\mathrm{X}}_{1}=\overrightarrow{\mathrm{X}}_{\alpha}-\overrightarrow{\mathrm{A}}_{1} \cdot\left(\overrightarrow{\mathrm{D}}_{\alpha}\right), \overrightarrow{\mathrm{X}}_{2}=\overrightarrow{\mathrm{X}}_{\beta}-\overrightarrow{\mathrm{A}}_{2} \cdot\left(\overrightarrow{\mathrm{D}}_{\beta}\right), \overrightarrow{\mathrm{X}}_{3}=\overrightarrow{\mathrm{X}}_{\delta}-\overrightarrow{\mathrm{A}}_{3} \cdot\left(\overrightarrow{\mathrm{D}}_{\delta}\right)$

Finally with the help of the top three grey wolves prey position knowledge, the new position vector is calculated by taking the average of the sum of three prey positions is given in the following equation

$\vec{X}(t+1)=\frac{\vec{x}_{1}+\overrightarrow{\mathrm{X}}_{2}+\overrightarrow{\mathrm{X}}_{3}}{3}$

Grey wolves typically search with the positions of alpha, beta, and delta wolves. Basically, the three wolves diverge with each other in searching the prey and then converge to attack the prey. The divergence property of the GRW is accentuated with the help of vector component $\overrightarrow{\mathrm{A}}$ having the random value between -1 to 1 and with the help of $\overrightarrow{\mathrm{C}}$ vector contains random values in $[0,2]$ to search the solutions globally. The convergence property of the GRW is accelerated with the component $\vec{a}$ by decrementing the value from 2 to 0 . The above convergence and divergence characteristics assist GRW to show random behavior in search, favoring better balance in maintaining the premature avoidance and long convergence search avoidance. The GRW algorithm for the extraction of maximum TLL is described below

\subsection{GRW algorithm}


Step 1: Initialize the objective function $\mathrm{F}_{1}$ mentioned in the section (2)

Step 2: Initialize the grey wolf position vector $\mathrm{X}\left(\mathrm{X}_{1}, \mathrm{X}_{2}, \ldots \mathrm{X}_{\mathrm{n}}\right)$ with the population size of 'NF $\mathrm{x} N$ '. Where 'NF' is the number of search agent grey wolves as 30 and ' $N$ ' is the number of individual incremental loading factor (IILF) pack size depends on the number of existing real power load connected in the test power system bus.

Step 3: Initialize the vector components $\overrightarrow{\mathrm{a}}, \overrightarrow{\mathrm{A}}, \overrightarrow{\mathrm{C}}$ and maximum number of iteration (ITER ${ }_{\text {Max }}$ ) which has been used in the GRW algorithm

Step 4: Calculate the fitness value using the objective function $F_{1}$ for the each position vector of grey wolf and identify the top three position vectors of prey. The first best $\left(\mathrm{X}_{\alpha}\right)$ prey position vector, the second best $\left(\mathrm{X}_{\beta}\right)$ prey position vector and the third best $\left(\mathrm{X}_{\delta}\right)$ prey position vector based on the fitness value.

Step 5: Using the top three prey position vector and with grey wolf position vector, update the positions of the top three best hunt wolves' position vectors such as $X_{1}, X_{2}$ and $X_{3}$ using the equations (12) and (13)

Step 6: Calculate the average of three position vector using the equation (14) and calculate its fitness value

Step 7: Compare the fitness value of current position vector of grey wolf with the newly created average position vector, if the fitness value is greater replace the current position vector for next iteration

Step 8: Repeat the step 4 to step 6 until the maximum iteration reaches

Step 9: Extract the optimal best IILF based on the fitness value of allowable TLL

Step 10: Repeat the step 1 to 9 by creating outage at all the transmission lines and extract the allowable TLL for each outage condition

Step 11: As discussed in the section (2.2), the minimized allowed TLL $\left(\mathrm{F}_{2}\right)$ with respect to the transmission line outage will be considered as the maximum allowable loadability of the system.

\subsection{Flower Pollination Algorithm (FPA)}

FPA based stochastic algorithm is exploited to resolve the optimization problem of extracting maximum allowable TLL with the optimal increment of IILF and also not violating the system security limits as given in the section 2.1. FPA is a nature inspired flower pollination behavior based optimization proposed by Xin-She Yang [29]. The core part of the FPA depends upon the two pollination methodology namely self-pollination and crosspollination. Self-pollination is the process of one flower pollinates the same flower or other flowers of the same plant whereas the cross-pollination is the process of pollination between two different plants. Global pollination is 
instigated by the biotic pollinating agents such as bees, bats, birds and flies. Biotic pollination agent follows the Levy distribution. Summarizing the following pollination characteristics as four regulations

1. Cross pollination act as a Global pollination and it is performing the Levy flights

2. Self-pollination is an abiotic local pollination act

3. Reproduction probability is assigned to flower constancy and is proportional to similarity of two flowers involved

4. The Probability has been tosses between 0 and 1 to control the cross pollination and self pollination. The pollination and reproduction of the fittest is given as below

$v_{i}^{t+1}=v_{i}^{t}+L\left(v_{i}^{t}-d^{*}\right)$

$\mathrm{L} \sim \frac{\mu \Gamma(\mu) \sin (\pi \mu / 2)}{\pi \pi} \frac{1}{\mathrm{~s}^{1+\mu}} \quad(\mathrm{s}>>\mathrm{SO}>0)$

Where $v_{i}^{t}$ is the pollen ' $i$ ' or solution vector $v_{i}$ at iteration $t$, and $d^{*}$ is the current best solution found among all solutions at the current generation/iteration. L is the strength of the pollination, which is a step size. Pollinators can move over a long distance with various distance steps, Levy flight distribution is used to mimic this characteristic efficiently. $\Gamma(\mu)$ is the standard gamma function, and this distribution is valid for large steps $s>0$. The local pollination and flower constancy can be represented as

$v_{i}^{t+1}=v_{i}^{t}+\varepsilon\left(v_{j}^{t}-v_{k}^{t}\right)$

Where $v_{j}^{t}$ and $v_{k}^{t}$ are pollens from the different flowers of the same plant species. This essentially mimics the flower constancy in a limited neighborhood. Mathematically, if $v_{j}^{t}$ and $v_{k}^{t}$ comes from the same species or selected from the same population, this become a local random walk if we draw ' $\varepsilon$ ' from a uniform distribution in $[0,1]$. The FPA algorithm structure for the extraction of maximum TLL is described below

Step 1: Initialize objective function $\mathrm{f} 1$ as mentioned in the section (2.1)

Step 2: Initialize a flower pollen population of $X\left(X_{1}, X_{2}, \ldots X_{n}\right)$ with the population size of 'NF $x$ '. Where 'NF' is the number of flowers as 30 and ' $\mathrm{N}$ ' is the number of IILF based on the existing load point in a power system.

Step 3: Extract the maximum fitness value in the initial population

Step 4: Initialize the switch probability p between $[0,1]$

While ( $\mathrm{t}<$ Maximum Iteration) 
For $\mathrm{i}=1: \mathrm{NF}$

If random value $<\mathrm{p}$,

Cross pollination has been processed via equation (15) via equation (16)

Else

Generate the $\varepsilon$ from a uniform distribution in $[0,1]$

Arbitrarily select the $\mathrm{j}^{\text {th }}$ and $\mathrm{k}^{\text {th }}$ flower among all the solutions

Do self-pollination via equation (17)

End if

Step 5: Determine the new fitness value for the extracted flower pollen population size

Step 6: If new fitness values is better than existing population fitness value, update them in the population

End for

Step 7: Locate the best solution in the current population based on the objective fitness value $\left(\mathrm{F}_{1}\right)$

End while

Step 8: Repeat the step 1 to 7 by creating outage at all the transmission lines and extract the allowable TLL for each outage condition

Step 9: As discussed in the section(2.2), the minimized allowed TLL $\left(\mathrm{F}_{2}\right)$ with respect to the transmission line outage will be considered as the maximum allowable loadability of the system.

\section{Results and Discussions}

The Proposed Maximum Allowable Total loadability limit (TLL) extraction methodology discussed in sections (2.2) and (2.3) has been tested using the three standard test systems such as IEEE 30, IEEE 57 and IEEE 118 buses. Newly evolved nature based inspired meta-heuristic algorithms such as Grey Wolf (GRW) optimizer and Flower pollination algorithm (FPA) are applied to extract the better solutions as discussed in the sections (3.2) and (3.3) using the MATLAB R2014a programming language. The brief structured data of the three test system with the base case real power and reactive load demands, the evaluated line loss with the critical voltage and its bus using the Standard Newton's Power Flow methodology are tabulated in the table -1 . The control parameters applied in the GRW and FPA are provided in the table -2 .

Table - 1 Base Case parameter of Implemented IEEE Test Systems 


\begin{tabular}{cccc}
\hline Total No of Existing Load connected Bus & 20 & 40 & 99 \\
Total No of Generator Bus & 6 & 7 & 54 \\
$\quad$ Total Transmission Line & 41 & 80 & 184 \\
$\begin{array}{c}\text { Existing Total Real power demand in Per } \\
\text { unit }\left(\sum \mathrm{P}_{\mathrm{Di}}\right)\end{array}$ & 1.892 & 12.25 & 42.42 \\
$\begin{array}{c}\text { Existing Total Reactive power demand in } \\
\quad \text { Per unit }\left(\sum \mathrm{Q}_{\mathrm{Di}}\right)\end{array}$ & 1.072 & 3.364 & 14.38 \\
$\quad$ & & 1.32863 \\
$\quad \begin{array}{c}\text { Total Real power line loss in Per } \\
\text { unit }\left(\sum \mathrm{P}_{\mathrm{Li}}\right)\end{array}$ & 0.0244 & 0.2786 & 7.8379 \\
$\quad$ & & \\
Total Reactive power line loss in Per & 0.0899 & 1.2167 & 0.943 \\
$\quad \begin{array}{c}\text { unit }\left(\sum \mathrm{P}_{\mathrm{Di}}\right) \\
\text { Critical Voltage Magnitude in Per unit }\end{array}$ & 0.961 & 0.936 & 76 \\
$\quad \begin{array}{c}\text { Critical Voltage Bus } \\
\text { Minimum Voltage Magnitude in Per unit }\end{array}$ & 0.95 & 31 & 0.94 \\
Maximum Voltage Magnitude in Per unit & 1.05 & 0.93 & 1.06 \\
\hline
\end{tabular}

Table - 2Applied Optimization Algorithm's Control Parameters

\begin{tabular}{c|c}
\hline Algorithm Control Parameters & FPA \\
\hline Flower population Size & 30 \\
Step Size & 2.5 \\
Gamma function parameter $(\mu)$ & 1.5 \\
Termination & 500 \\
\hline & GRW \\
Wolves population Size & 30 \\
Termination & 500 \\
Vectors $\overrightarrow{\mathbf{r}}$ and $\overrightarrow{\mathrm{r}} \mathbf{2}$ & Random value between 0 and 1 \\
$\overrightarrow{\mathrm{a}}$ component & Linearly decreased from 2 to 0 \\
\cline { 2 - 2 }
\end{tabular}

The implemented test results are detailed in the below sections as follow

4.1. Maximum allowable TLL extraction in Base case scenario

GRW and FPA based determination of Maximum allowable TLL by extracting the Optimal incremental loading

\begin{tabular}{llllllllll}
\hline Bus & GRW & FPA & GRW & FPA & Bus & GRW & FPA & GRW & FPA \\
\hline
\end{tabular}

factor in each load bus without affecting the system's security constraints are tested in the IEEE 30, 57,118 bus systems and its newly predicted real power demand for each loaded bus at the base case scenario with its individual incremental loading factor (IILF) are updated in the tables 3, 4 and 5 respectively.

Table - 3 Optimal Base case IILF and real power demand of each load in IEEE 30 Bus system 


\begin{tabular}{crrrrrrrrr}
\hline & \multicolumn{2}{c}{$\begin{array}{c}\text { Total Real power } \\
\text { load in p.u }\end{array}$} & \multicolumn{2}{c}{ IILF Factor $(\boldsymbol{\lambda})$} & \multicolumn{3}{c}{$\begin{array}{c}\text { Total Real power } \\
\text { load in p.u }\end{array}$} & \multicolumn{2}{c}{ IILF Factor( $\boldsymbol{\lambda})$} \\
\hline $\mathbf{2}$ & 0.433282 & 0.433977 & 0.9967 & 0.9999 & $\mathbf{1 7}$ & 0.092173 & 0.101521 & 0.0241 \\
$\mathbf{3}$ & 0.047977 & 0.038546 & 0.999 & 0.6061 & $\mathbf{1 8}$ & 0.041532 & 0.039762 & 0.2979 & 0.2426 \\
$\mathbf{4}$ & 0.15184 & 0.150864 & 0.9979 & 0.9851 & $\mathbf{1 9}$ & 0.107982 & 0.112253 & 0.1367 & 0.1816 \\
$\mathbf{7}$ & 0.433293 & 0.450904 & 0.9004 & 0.9776 & $\mathbf{2 0}$ & 0.027608 & 0.026363 & 0.2549 & 0.1983 \\
$\mathbf{8}$ & 0.300562 & 0.300748 & 0.0019 & 0.0025 & $\mathbf{2 1}$ & 0.306348 & 0.215256 & 0.7506 & 0.23 \\
$\mathbf{1 0}$ & 0.059645 & 0.069808 & 0.0284 & 0.2036 & $\mathbf{2 3}$ & 0.061536 & 0.060661 & 0.923 & 0.8957 \\
$\mathbf{1 2}$ & 0.196697 & 0.195712 & 0.7562 & 0.7474 & $\mathbf{2 4}$ & 0.158948 & 0.170408 & 0.827 & 0.9587 \\
$\mathbf{1 4}$ & 0.114549 & 0.093991 & 0.8476 & 0.516 & $\mathbf{2 6}$ & 0.041072 & 0.044636 & 0.1735 & 0.2753 \\
$\mathbf{1 5}$ & 0.088757 & 0.124373 & 0.0824 & 0.5167 & $\mathbf{2 9}$ & 0.028308 & 0.030417 & 0.1795 & 0.2674 \\
$\mathbf{1 6}$ & 0.036596 & 0.061004 & 0.0456 & 0.743 & $\mathbf{3 0}$ & 0.138717 & 0.139522 & 0.3087 & 0.3162 \\
\hline
\end{tabular}

Table - 40ptimal Base case IILF and real power demand of each load in IEEE 57 Bus system

\begin{tabular}{|c|c|c|c|c|c|c|c|c|c|}
\hline \multirow{2}{*}{$\begin{array}{c}\text { Bus } \\
\text { Number }\end{array}$} & GRW & FPA & GRW & FPA & \multirow{2}{*}{$\begin{array}{c}\text { Bus } \\
\text { Number }\end{array}$} & GRW & FPA & GRW & FPA \\
\hline & \multicolumn{2}{|c|}{$\begin{array}{c}\text { Total Real power } \\
\text { load in p.u }\end{array}$} & \multicolumn{2}{|c|}{ IILF Factor $(\lambda)$} & & \multicolumn{2}{|c|}{$\begin{array}{l}\text { Total Real power } \\
\text { load in p.u }\end{array}$} & \multicolumn{2}{|c|}{ IILF Factor( $(\lambda)$} \\
\hline 1 & 1.099695 & 1.088195 & 0.9994 & 0.9785 & 29 & 0.176587 & 0.177955 & 0.0387 & 0.0468 \\
\hline 2 & 0.03842 & 0.036154 & 0.2807 & 0.2051 & 30 & 0.036032 & 0.036048 & 0.0009 & 0.0013 \\
\hline 3 & 0.819388 & 0.807246 & 0.9985 & 0.9689 & 31 & 0.058052 & 0.058106 & 0.0009 & 0.0018 \\
\hline 5 & 0.229115 & 0.236032 & 0.7624 & 0.8156 & 32 & 0.016029 & 0.016004 & 0.0018 & 0.0002 \\
\hline 6 & 0.795567 & 0.803429 & 0.0608 & 0.0712 & 33 & 0.038036 & 0.038002 & 0.0009 & 0.0001 \\
\hline 8 & 2.020999 & 2.043847 & 0.3473 & 0.3626 & 35 & 0.060098 & 0.060301 & 0.0016 & 0.005 \\
\hline 9 & 1.217109 & 1.250144 & 0.0059 & 0.0332 & 38 & 0.140947 & 0.140547 & 0.0068 & 0.0039 \\
\hline 10 & 0.056656 & 0.05617 & 0.1331 & 0.1234 & 41 & 0.064041 & 0.064572 & 0.0165 & 0.025 \\
\hline 12 & 5.343294 & 5.0613 & 0.4173 & 0.3425 & 42 & 0.071912 & 0.071672 & 0.0128 & 0.0095 \\
\hline 13 & 0.182735 & 0.186999 & 0.0152 & 0.0389 & 43 & 0.022612 & 0.023941 & 0.1306 & 0.197 \\
\hline 14 & 0.110993 & 0.119924 & 0.0571 & 0.1421 & 44 & 0.120902 & 0.121518 & 0.0075 & 0.0127 \\
\hline 15 & 0.225738 & 0.231918 & 0.0261 & 0.0542 & 47 & 0.299585 & 0.302832 & 0.0087 & 0.0196 \\
\hline 16 & 0.856814 & 0.819954 & 0.9926 & 0.9069 & 49 & 0.183338 & 0.182763 & 0.0185 & 0.0153 \\
\hline 17 & 0.838349 & 0.83406 & 0.9961 & 0.9859 & 50 & 0.213503 & 0.215846 & 0.0167 & 0.0278 \\
\hline 18 & 0.278469 & 0.279994 & 0.0238 & 0.0294 & 51 & 0.259828 & 0.285577 & 0.4435 & 0.5865 \\
\hline 19 & 0.033551 & 0.034374 & 0.0167 & 0.0416 & 52 & 0.055542 & 0.054041 & 0.1335 & 0.1029 \\
\hline 20 & 0.023308 & 0.023602 & 0.0134 & 0.0262 & 53 & 0.206608 & 0.210145 & 0.033 & 0.0507 \\
\hline 23 & 0.063444 & 0.063721 & 0.007 & 0.0114 & 54 & 0.049018 & 0.046072 & 0.1956 & 0.1237 \\
\hline 25 & 0.06309 & 0.063172 & 0.0014 & 0.0027 & 55 & 0.07287 & 0.094907 & 0.0716 & 0.3957 \\
\hline 27 & 0.093167 & 0.093556 & 0.0018 & 0.006 & 56 & 0.076169 & 0.077011 & 0.0022 & 0.0133 \\
\hline 28 & 0.0466 & 0.046787 & 0.013 & 0.0171 & 57 & 0.067933 & 0.068345 & 0.0139 & 0.0201 \\
\hline
\end{tabular}

Table - 5 Optimal Base case IILF and real power demand of each load in IEEE 118 Bus system

\begin{tabular}{llllllllll}
\hline Bus & GRW & FPA & GRW & FPA & Bus & GRW & FPA & GRW & FPA \\
\hline
\end{tabular}




\begin{tabular}{|c|c|c|c|c|c|c|c|c|c|}
\hline \multirow{2}{*}{$\begin{array}{c}\text { Number } \\
1\end{array}$} & \multicolumn{2}{|c|}{$\begin{array}{l}\text { Total Real power } \\
\text { load in p.u }\end{array}$} & \multicolumn{2}{|c|}{ IILF Factor( $\lambda)$} & \multirow{2}{*}{$\begin{array}{c}\text { Number } \\
59\end{array}$} & \multicolumn{2}{|c|}{$\begin{array}{c}\text { Total Real power load } \\
\text { in p.u }\end{array}$} & \multicolumn{2}{|c|}{ IILF Factor( $(\lambda)$} \\
\hline & 0.821904 & 0.80006 & 0.6116 & 0.5687 & & 5.534329 & 5.538662 & 0.998 & 0.9995 \\
\hline 2 & 0.293678 & 0.291941 & 0.4684 & 0.4597 & 60 & 1.503009 & 1.55064 & 0.9269 & 0.988 \\
\hline 3 & 0.482425 & 0.503857 & 0.237 & 0.2919 & 62 & 1.508317 & 1.532296 & 0.9589 & 0.99 \\
\hline 4 & 0.427469 & 0.418715 & 0.0961 & 0.0736 & 66 & 0.773426 & 0.777897 & 0.9831 & 0.9946 \\
\hline 6 & 0.683728 & 0.681984 & 0.3149 & 0.3115 & 67 & 0.513867 & 0.514672 & 0.8352 & 0.8381 \\
\hline 7 & 0.253922 & 0.253265 & 0.3364 & 0.333 & 70 & 1.138176 & 1.137176 & 0.7245 & 0.723 \\
\hline 8 & 0.493001 & 0.458246 & 0.7607 & 0.6366 & 72 & 0.143314 & 0.14171 & 0.1943 & 0.1809 \\
\hline 11 & 0.753219 & 0.759095 & 0.076 & 0.0844 & 73 & 0.068122 & 0.066885 & 0.1354 & 0.1148 \\
\hline 12 & 0.550342 & 0.545269 & 0.1709 & 0.1601 & 74 & 0.928876 & 0.928103 & 0.366 & 0.3649 \\
\hline 13 & 0.54755 & 0.546472 & 0.6104 & 0.6073 & 75 & 0.483609 & 0.475694 & 0.029 & 0.0121 \\
\hline 14 & 0.180065 & 0.178024 & 0.2862 & 0.2716 & 76 & 0.724669 & 0.704692 & 0.0657 & 0.0363 \\
\hline 15 & 1.065323 & 1.064572 & 0.1837 & 0.1829 & 77 & 1.035391 & 1.030705 & 0.6974 & 0.6897 \\
\hline 16 & 0.265704 & 0.266758 & 0.0628 & 0.067 & 78 & 1.149132 & 1.145119 & 0.6185 & 0.6128 \\
\hline 17 & 0.125971 & 0.122291 & 0.1452 & 0.1117 & 79 & 0.69983 & 0.68824 & 0.7944 & 0.7647 \\
\hline 18 & 0.692428 & 0.708218 & 0.154 & 0.1804 & 80 & 2.425935 & 2.556005 & 0.8661 & 0.9662 \\
\hline 19 & 0.725789 & 0.696901 & 0.6129 & 0.5487 & 82 & 0.785303 & 0.798818 & 0.4543 & 0.4793 \\
\hline 20 & 0.268527 & 0.263733 & 0.4918 & 0.4652 & 83 & 0.204848 & 0.216375 & 0.0242 & 0.0819 \\
\hline 21 & 0.160424 & 0.156712 & 0.1459 & 0.1194 & 84 & 0.185019 & 0.184694 & 0.682 & 0.679 \\
\hline 22 & 0.134895 & 0.130368 & 0.3489 & 0.3037 & 85 & 0.35647 & 0.332518 & 0.4853 & 0.3855 \\
\hline 23 & 0.071152 & 0.072392 & 0.0165 & 0.0342 & 86 & 0.395239 & 0.377004 & 0.8821 & 0.7953 \\
\hline 24 & 0.216468 & 0.215608 & 0.6651 & 0.6585 & 88 & 0.608279 & 0.627124 & 0.2672 & 0.3065 \\
\hline 27 & 0.819682 & 0.808425 & 0.1545 & 0.1386 & 90 & 2.276467 & 2.219436 & 0.3966 & 0.3616 \\
\hline 28 & 0.252992 & 0.255721 & 0.4882 & 0.5042 & 91 & 0.118063 & 0.118913 & 0.1806 & 0.1891 \\
\hline 29 & 0.339799 & 0.335735 & 0.4158 & 0.3989 & 92 & 1.165975 & 1.139526 & 0.7938 & 0.7531 \\
\hline 31 & 0.435797 & 0.43955 & 0.0135 & 0.0222 & 93 & 0.214998 & 0.220307 & 0.7917 & 0.8359 \\
\hline 32 & 0.638462 & 0.635879 & 0.0821 & 0.0778 & 94 & 0.499032 & 0.497875 & 0.6634 & 0.6596 \\
\hline 33 & 0.273483 & 0.269623 & 0.1891 & 0.1723 & 95 & 0.650441 & 0.68437 & 0.5487 & 0.6295 \\
\hline 34 & 0.64692 & 0.653036 & 0.0965 & 0.1068 & 96 & 0.423682 & 0.41655 & 0.115 & 0.0962 \\
\hline 35 & 0.396695 & 0.391181 & 0.2021 & 0.1854 & 97 & 0.196286 & 0.195583 & 0.3086 & 0.3039 \\
\hline 36 & 0.403586 & 0.419105 & 0.3019 & 0.352 & 98 & 0.446257 & 0.45083 & 0.3125 & 0.326 \\
\hline 39 & 0.519448 & 0.50558 & 0.9239 & 0.8725 & 99 & 0.602975 & 0.598288 & 0.4357 & 0.4245 \\
\hline 40 & 1.139372 & 1.173934 & 0.7263 & 0.7787 & 100 & 0.462554 & 0.472405 & 0.2501 & 0.2768 \\
\hline 41 & 0.713564 & 0.729947 & 0.9286 & 0.9728 & 101 & 0.252062 & 0.245284 & 0.1457 & 0.1149 \\
\hline 42 & 1.303333 & 1.323012 & 0.3576 & 0.3781 & 102 & 0.074542 & 0.076717 & 0.4908 & 0.5343 \\
\hline 43 & 0.218329 & 0.222343 & 0.2129 & 0.2352 & 103 & 0.277003 & 0.277419 & 0.2044 & 0.2062 \\
\hline 44 & 0.177175 & 0.170152 & 0.1073 & 0.0634 & 104 & 0.618434 & 0.584841 & 0.6275 & 0.5391 \\
\hline 45 & 0.988033 & 1.058952 & 0.8642 & 0.998 & 105 & 0.480056 & 0.497041 & 0.5486 & 0.6034 \\
\hline 46 & 0.555694 & 0.551585 & 0.9846 & 0.9699 & 106 & 0.509245 & 0.501277 & 0.1843 & 0.1658 \\
\hline 47 & 0.595614 & 0.586843 & 0.7518 & 0.726 & 107 & 0.786805 & 0.76989 & 0.5736 & 0.5398 \\
\hline 48 & 0.290236 & 0.295842 & 0.4512 & 0.4792 & 108 & 0.022528 & 0.022647 & 0.1264 & 0.1324 \\
\hline 49 & 1.718026 & 1.734802 & 0.9747 & 0.994 & 109 & 0.122198 & 0.124062 & 0.5275 & 0.5508 \\
\hline 50 & 0.215207 & 0.219273 & 0.2659 & 0.2898 & 110 & 0.484102 & 0.49351 & 0.2413 & 0.2654 \\
\hline 51 & 0.251715 & 0.245866 & 0.4807 & 0.4463 & 112 & 0.719564 & 0.737387 & 0.0582 & 0.0844 \\
\hline 52 & 0.205871 & 0.208209 & 0.1437 & 0.1567 & 113 & 0.065533 & 0.062551 & 0.0922 & 0.0425 \\
\hline 53 & 0.23734 & 0.236013 & 0.0319 & 0.0261 & 114 & 0.114601 & 0.114173 & 0.4325 & 0.4272 \\
\hline 54 & 2.227206 & 2.258996 & 0.971 & 0.9991 & 115 & 0.304804 & 0.29891 & 0.3855 & 0.3587 \\
\hline 55 & 1.217879 & 1.228732 & 0.9331 & 0.9504 & 116 & 3.673752 & 3.67823 & 0.9966 & 0.999 \\
\hline 56 & 1.628714 & 1.673129 & 0.9389 & 0.9918 & 117 & 0.229224 & 0.225434 & 0.1461 & 0.1272 \\
\hline 57 & 0.148261 & 0.144672 & 0.2355 & 0.2056 & 118 & 0.336364 & 0.33326 & 0.0193 & 0.0099 \\
\hline 58 & 0.130577 & 0.136889 & 0.0881 & 0.1407 & & & & & \\
\hline
\end{tabular}


It is inferred from the table-3; table- 4 and table-5 that the FPA and GRW based optimal IILF are more or less equal with slight variation which helps to confirm the correctness of the applied algorithmic solutions with respect to any number of search parameter variations. To check the effectiveness of the proposed IILF based maximum loading point determination, the system's maximum loading capacity extracted from the optimal variable IILF based method using FPA and GRW are compared with the optimal constant incremental loading factor based methods via PSO, HPSO, MAPSO, MAHPSO, DE, DEPSO and its results are tabulated in the table6.

Table - 6 Comparison of Maximum allowable TLL of the Test Systems

\begin{tabular}{|c|c|c|c|c|c|c|}
\hline \multirow[t]{2}{*}{ Algorithms } & \multicolumn{3}{|c|}{$\begin{array}{c}\text { Maximum Total loadability limit of the Test } \\
\text { System in p.u }\end{array}$} & \multicolumn{3}{|c|}{$\begin{array}{c}\text { Percentage Increase of Maximum } \\
\text { Demand from the existing loadability } \\
\text { condition }\end{array}$} \\
\hline & $\begin{array}{l}\text { IEEE } 30 \text { Bus } \\
\text { System }\end{array}$ & $\begin{array}{c}\text { IEEE 57 } \\
\text { Bus System }\end{array}$ & $\begin{array}{c}\text { IEEE } 118 \\
\text { Bus System }\end{array}$ & $\begin{array}{c}\text { IEEE 30 } \\
\text { Bus system }\end{array}$ & $\begin{array}{c}\text { IEEE 57 } \\
\text { Bus System }\end{array}$ & $\begin{array}{c}\text { IEEE } 118 \\
\text { Bus system }\end{array}$ \\
\hline PSO & 2.6010 & 14.039 & 56.443 & 37.4736 & 12.312 & 33.057 \\
\hline HPSO & 2.6035 & 14.062 & 56.445 & 37.6057 & 12.496 & 33.062 \\
\hline MAPSO & 2.6080 & NA & 56.449 & 37.8488 & NA & 33.071 \\
\hline MAHPSO & 2.6081 & NA & 56.45 & 37.8478 & NA & 33.074 \\
\hline DE & 2.6709 & NA & 56.6212 & 41.1681 & NA & 33.477 \\
\hline DEPSO & 2.6974 & NA & 57.016 & 42.5687 & NA & 34.408 \\
\hline FPA & 2.8607 & 16.52 & 65.19 & 49.9471 & 32.16 & 53.677 \\
\hline GRWO & 2.8674 & 16.72 & 65.43 & 51.3742 & 33.76 & 54.240 \\
\hline RPF & 2.6 & 14.2 & 56.4 & 38.02 & 15.92 & 32.96 \\
\hline
\end{tabular}

The comparison results will be the evidence for the enhancement of system loadability limit to the great

extent from the base case condition in variable loading demand based TLL extraction. The above evidence is illustrated with the help of comparison based on the percentage increase of maximum loadability from the existing loading condition of the system.

The convergence result graph of the GRW and FPA has depicted in the Figures from 1 to 3 for the IEEE 30, 57 and

118 bus systems respectively.
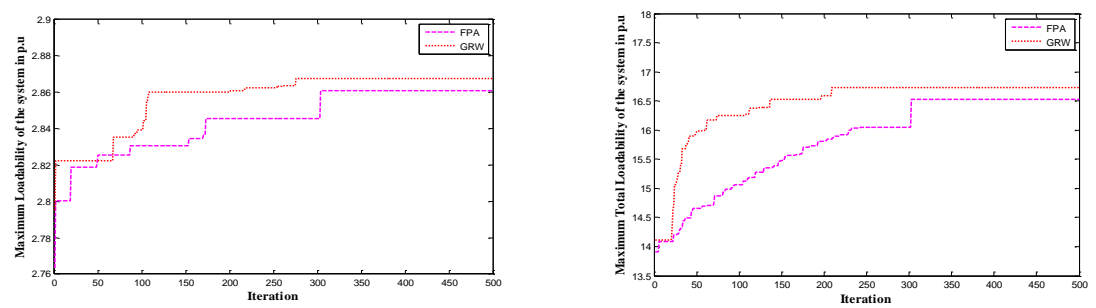

Fig.2Base case convergence graph

Fig.1 Base case con
convergence graph

of IEEE 30 Bus test system

test system

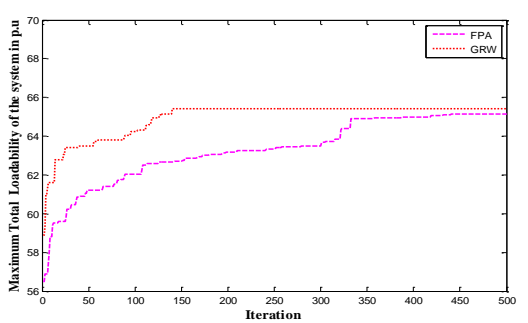

Fig.3 Base case

of IEEE 57 Bus test system of IEEE 118 Bus 
The inference of the convergence graph shows that the GRW has better solution and also better balance in the exploration and exploitation search than FPA while extracting the maximum loadability of the system with respect to the number of IILF variations based on the structure of the power system. The voltage profile of the IEEE 30, 57 and 118 bus systems at the FPA and GRW based optimal loading point condition are depicted in the figure 4, 5 and 6 respectively. It is inferred from the voltage profile that the extraction of the maximum loading point is done at the critical margin of the system voltage level without violating the system voltage limits.

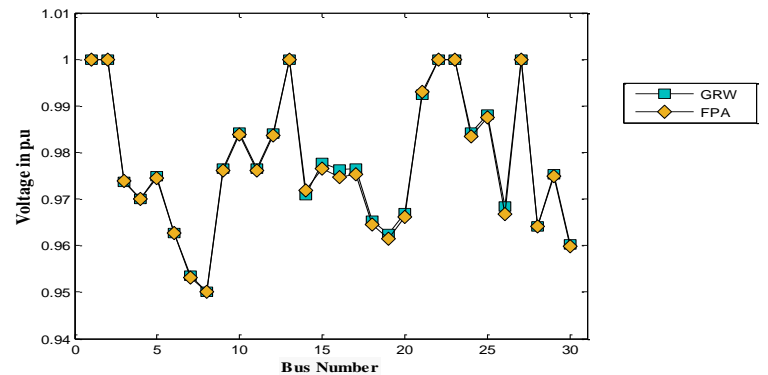

Fig.4. Optimal loadability based Voltage graph in IEEE 30 Bus test system

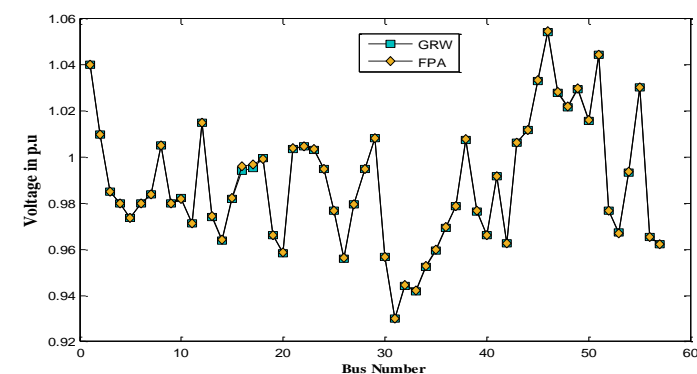

Fig.5. Optimal loadability based Voltage graph in IEEE 57 Bus test system

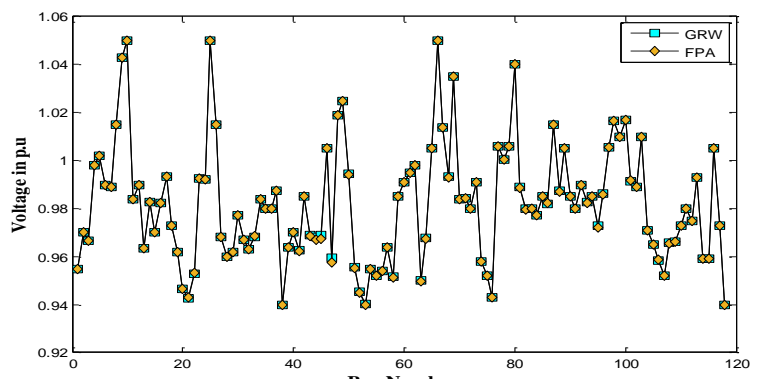

Fig.6. Optimal loadability based Voltage graph in IEEE 118 Bus test system

Statistical measures such as mean, best, worst, standard deviation and convergence iteration helps to evaluate the performance of the optimization algorithm. The performance of GRW and FPA based optimization of maximum loading point extraction are evaluated by conducting 20 different trails and its parametric measures are updated in the table -7 . The inference of the performance table clearly indicates that both the FPA and GRW are exceptionally good in extracting the best objective solutions but in terms of standard deviation GRW helps to provide better search solution with respect to any number of iteration and also the convergence rate is better compared to the FPA.

Table - 7 Statistical measures of GRW and FPA 


\begin{tabular}{ccccccc}
\hline $\begin{array}{c}\text { Test } \\
\text { System }\end{array}$ & Algorithm & Worst & Mean & Best & $\begin{array}{c}\text { Standard } \\
\text { Deviation }\end{array}$ & $\begin{array}{c}\text { No of } \\
\text { Iteration for } \\
\text { convergence }\end{array}$ \\
\hline 30 Bus & FPA & 2.8351 & 2.845 & 2.860 & 0.0083 & 320 \\
& GRW & 2.8521 & 2.859 & 2.867 & 0.0043 & 125 \\
57 Bus & FPA & 15.286 & 15.672 & 16.52 & 0.2279 & 280 \\
& GRW & 16.584 & 16.669 & 16.72 & 0.0508 & 300 \\
118 Bus & FPA & 63.578 & 64.137 & 65.19 & 0.4885 & 210 \\
& GRW & 64.526 & 64.964 & 65.43 & 0.3302 & 220 \\
\hline
\end{tabular}

\subsection{Maximum allowable TLL extraction in line contingency scenario}

Total loadability limits (TLL) for all the allowable single line outages from the transmission line are manipulated using FPA and GRW based optimization algorithm. Based on the severity of the line contingency, the TLL will be decreased from the base case value. So, the manipulated results are sorted in descending order and the top five ranking line outages along with base case scenario were taken out. The extracted results are tabulated in the table -8 for all the three test system.

Table - 8 Allowable Contingency Severity ranking of different bus systems

\begin{tabular}{cccc}
\hline $\begin{array}{c}\text { Allowable Contingency } \\
\text { Severity ranking }\end{array}$ & Severe Line Outage & $\begin{array}{c}\text { FPA TLL } \\
\text { in Per unit }\end{array}$ & $\begin{array}{c}\text { GRW TLL } \\
\text { In Per Unit }\end{array}$ \\
\hline $\mathbf{1}$ & IEEE 30 Bus System & & \\
$\mathbf{2}$ & $\mathbf{5}-\mathbf{7}$ & 2.1254 & 2.1694 \\
$\mathbf{3}$ & $\mathbf{2}-\mathbf{6}$ & 2.1492 & 2.1881 \\
$\mathbf{4}$ & $\mathbf{2}-\mathbf{5}$ & 2.275 & 2.2782 \\
$\mathbf{5}$ & $\mathbf{2}-\mathbf{4}$ & 2.4456 & 2.4587 \\
& $\mathbf{1}-\mathbf{3}$ & 2.4692 & 2.4835 \\
& Base Case & 2.8607 & 2.8674 \\
$\mathbf{1}$ & IEEE 57 Bus System & 14.1328 & \\
$\mathbf{2}$ & $\mathbf{1 2}-\mathbf{1 3}$ & 14.3645 & 14.2568 \\
$\mathbf{3}$ & $\mathbf{1 2}-\mathbf{1 6}$ & 16.0953 & 14.3758 \\
$\mathbf{4}$ & $\mathbf{2 3}-\mathbf{2 4}$ & 16.2051 & 16.118 \\
$\mathbf{5}$ & $\mathbf{1 1}-\mathbf{4 3}$ & 16.2937 & 16.2107 \\
& $\mathbf{7}-\mathbf{8}$ & 16.5267 & 16.3921 \\
& Base Case & & \\
$\mathbf{1}$ & IEEE 118 Bus System & 57.1418 & \\
$\mathbf{2}$ & $\mathbf{6 9 - 7 0}$ & 59.8238 & 58.0465 \\
$\mathbf{3}$ & $\mathbf{6 9}-\mathbf{7 7}$ & 60.0502 & 60.2258 \\
$\mathbf{4}$ & $\mathbf{2 6}-\mathbf{3 0}$ & 60.9535 & 60.3762 \\
$\mathbf{5}$ & $\mathbf{6 4}-\mathbf{6 5}$ & 61.2438 & 61.1771 \\
& $\mathbf{3 0}-\mathbf{3 8}$ & 65.1957 & 65.42925 \\
\hline
\end{tabular}


Both the FPA and GRW help to provide the same ranking results in terms of line outage. The transmission line outage from bus 5 and bus 7, the line outage from the bus 12 and bus 13, the line outage from the bus 69 and bus 70 will be considered as the allowable severe line contingencies for the IEEE 30, 57 and 118 bus systems respectively. The GRW TLL results of severe line outages are better compared to FPA and also the GRW based results shows better convergence and searching balance which is evident from the convergence graphs. These graphs are given in figure 7, 8 and 9 for the 30,57 and 118 bus systems respectively. So, the GRW based minimized severe line outage TLL are predicted as the Maximum allowable total loadability limit of the system.
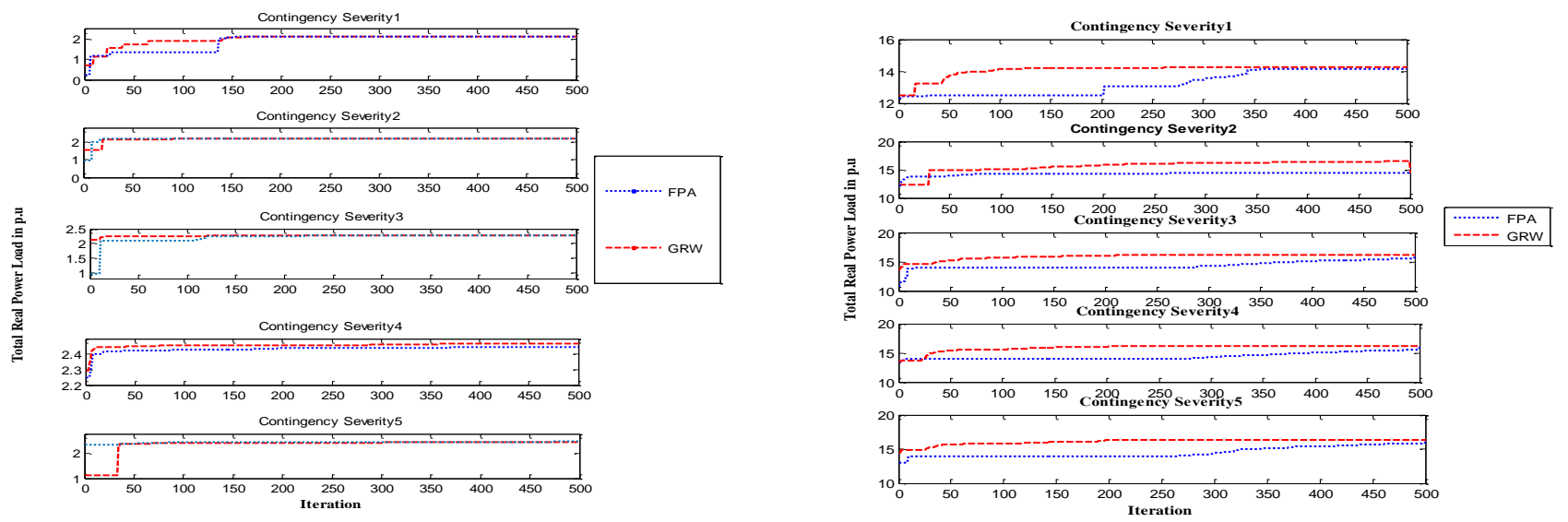

\section{Fig.7Contingency Cases convergence graph of IEEE 57}

BusIEEE 30 Bus Test system

Fig.8 Contingency Cases convergence graph of

\section{Test system}

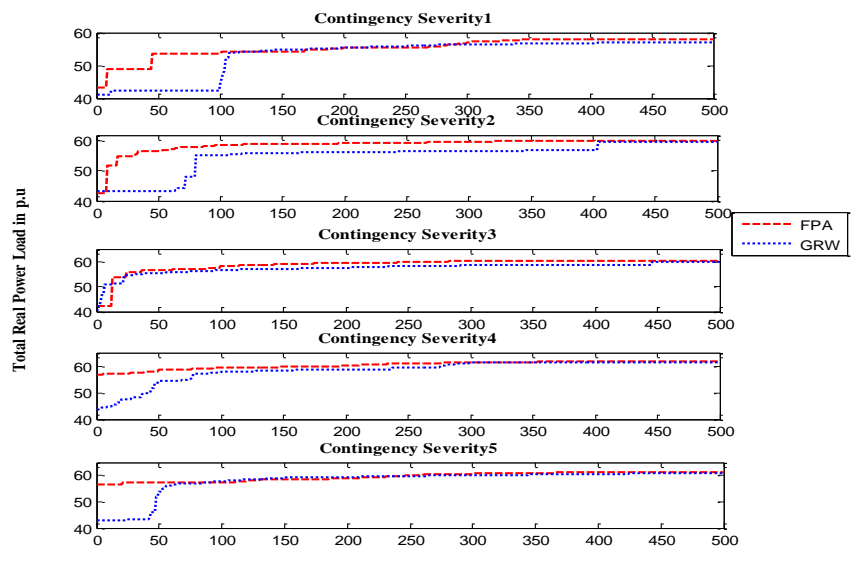

Fig.9 Contingency Cases convergence graph of IEEE 118 Bus Test system

\section{Conclusion}

The proposed approach of predicting maximum allowable total loadability limit through optimal determination of IILF helps to augment the load utilization level which in turn improvises the agility of the power system in 
sustaining system's power balance with respect to any additional load inclusion and also at any unbalanced scenarios. The forecasting of allowable incremental loading capacity in each loading point helps the producer or power supplier to choose the better bus position for the injection of power supply and also helps the customer to extract the load from the better load bus. Since both the producers and consumers are benefited, the proposed approach paves the path for achieving the socio-economic benefits. The statistical results of the optimization algorithm confirms that the application of modern meta-heuristics optimization such as GRW and FPA helps to extract better solutions by maintaining the balanced intensification and diversification search process with respect to any number of search parameter variations.

\section{References}

M.R. Mansour, L.F.C. Alberto, R.A. Ramos, Preventive control design for voltage stability considering multiple critical contingencies, IEEE Trans. Power Syst.31 (March (2)) (2016) 1517-1525.

P. Prakash, D.K. Khatod, Optimal sizing and siting techniques for distributed generation in distribution systems: a review, Renew. Sustain. Energy Rev. 57(2016) 111-130.

L. Rocha, R. Castro, J.M.F. de Jesus, An improved particle swarm optimization algorithm for optimal placement and sizing of STATCOM, Int. Trans. Electr.Energy Syst. 26 (4) (2016) 825-840.

M. Saravanan, S.M.R. Slochanal, P. Venkatesh, J.P.S. Abraham, Application of particle swarm optimization technique for optimal location of FACTS devices considering cost of installation and system loadability, Electr. Power Syst. Res.77 (3-4) (2007) 276-283.

Y.-C. Chang, Multi-objective optimal thyristor controlled series compensator installation strategy for transmission system loadability enhancement, Gener.Transm. Distrib. IET 8 (March (3)) (2014) 552-562.

P. Acharjee, Identification of maximum loadability limit and weak buses using security constraint genetic algorithm, Int. J. Electr. Power Energy Syst. 36 (1)(2012) 40-50.

S.D. Naik, M.K. Khedkar, S.S. Bhat, Effect of line contingency on static voltage stability and maximum loadability in large multi bus power system, Int. J.Electr. Power Energy Syst. 67 (2015) 448-452.

A.J. Conejo, L.B. Morales, S.J. Kazempour, A.S. Siddiqui, Investment in Electricity Generation and Transmission, Springer International Publishing,2016. 
Amgad, A EL-Dib., Hosam, K.M Youssef., EL-Metwally, M.M., Osrnan, Z.: Maximum loadability of power systems using hybrid particle swarm optimization. Electr Power Syst Res ,76:485-92,( 2006)

N. Alguacil, A.L. Motto, A.J. Conejo, Transmission expansion planning: a mixed-integer LP approach, IEEE Trans. Power Syst. 18 (August (3)) (2003)1070-1077.

Z. Hu, X. Wang, Efficient computation of maximum loading point by load flow method with optimal multiplier, Power Syst. IEEE Trans. 23 (May (2)) (2008)804-806.

A. Kazemi, B. Badrzadeh, Modeling and simulation of SVC and TCSC to study their limits on maximum loadability point, Int. J. Electr. Power Energy Syst. 26(8) (2004) 619-626.

C. Gómez-Quiles, A. Gómez-Expósito, W. Vargas, Computation of maximum loading points via the factored load flow, IEEE Trans. Power Syst. 31 (5) (2016)4128-4134.

G. Yang, G. Hovland, R. Majumder, Z. Dong, TCSC allocation based on line flow based equations via mixedinteger programming, Power and Energy Society General Meeting-Conversion and Delivery of Electrical Energy in the 21stCentury, 2008 IEEE (2008), p. 1.

M. Pourakbari-Kasmaei, M.J. Rider, J.R.S. Mantovani, An unequivocal normalization-based paradigm to solve dynamic economic and emission active-reactive OPF (optimal power flow), Energy 73 (2014) 554-566.

F. Milano, C.A. Canizares, M. Invernizzi, Multi objective optimization for pricing system security in electricity markets, Power Syst. IEEE Trans. 18 (May(2)) (2003) 596-604.

A.L. Ara, A. Kazemi, S.A.N. Niaki, Multi objective optimal location of FACTS shunt-series controllers for power system operation planning, IEEE Trans.PowerDeliv. 27 (April (2)) (2012) 481-490.

S. Binato, M.V.F. Pereira, S. Granville, A new Benders decomposition approach to solve power transmission network design problems, IEEE Trans. Power Syst. 16 (May (2)) (2001) 235-240.

G.D. Irisarri, X. Wang, J. Tong, S. Mokhtari, Maximum loadability of power systems using interior point nonlinear optimization method, Power Syst. IEEE Trans. 12 (February (1)) (1997) 162-172.

I. El-Samahy, K. Bhattacharya, C. Canizares, M.F. Anjos, J. Pan, A procurement market model for reactive power services considering system security, IEEE Trans. Power Syst. 23 (February (1)) (2008) 137-149.

A.A. EL-Dib, H.K.M. Youssef, M.M. EL-Metwally, Z. Osman, Maximum loadability of power systems using hybrid particle swarm optimization, Electr. Power Syst. Res. 76 (6-7) (2006) 485-492. 
M.M.A. Abdelaziz, E.F. El-Saadany, Maximum loadability consideration in droop-controlled islanded micro grids optimal power flow, Electr. Power Syst.Res. 106 (2014) 168-179.

T. Van Cutsem, Voltage instability: phenomena, countermeasures, and analysis methods, Proc. IEEE 88 (February (2)) (2000) 208-227.

Shunmugalatha, A., Mary Raja Slochanal, S.: Maximum loadability of a power system using multi agent-based hybrid particle swarm optimization. Electr Power Compon Syst,36:575-86, (2008)

Gnanambal, K., Babulal, C.K.: Maximum loadability limit of power system using hybrid differential evolution with particle swarm optimization. Electrical Power and Energy Systems 43 ,150-155, (2012)

SeyedaliMirjalili, Seyed Mohammad Mirjalili, Andrew Lewis: Grey Wolf Optimizer. Advances in Engineering Software 69 (2014) 46-61

Mech LD. Alpha status, dominance, and division of labor in wolf packs. Can J Zool 1999;77:1196-203.

Muro C, Escobedo R, Spector L, Coppinger R. Wolf-pack (Canis lupus) hunting strategies emerge from simple rules in computational simulations. Behav Process 2011;88:192-7.

Xin-She Yang, Flower pollination algorithm for global optimization, in: Unconventional Computation and Natural Computation 2012, Lecture Notes in Computer Science, Vol. 7445, pp. 240-249 (2012). 